\title{
COMPUTING GRAYSCALE OF FACE DETECTION MENGGUNAKAN METODE SOBEL DAN LAPLACIAN OF GAUSSIAN
}

\author{
Kustanto \\ Jurusan Informatika Fakultas Teknologi Informasi, Universitas Islam Balitar Blitar \\ email : kustanto@unisbablitar.ac.id
}

\begin{abstract}
Abstrak : Citra dari sudut pandang matematis, merupakan fungsi menerus atau continue dari intensitas cahaya pada bidang dua dimensi $f(x, y)$, dengan $x$ dan $y$ adalah koordinat spasial dan amplitude $f$ pada pasangan koordinat $(x, y)$ yang disebut intensitas atau derajat keabuan citra pada titik tersebut. Jika $x, y$, dan semuanya berhingga, dan nilainya diskrit, citra tersebut merupakan citra digital Citra digital adalah citra yang disimpan dalam format digital atau dalam bentuk file. "Pengolahan citra digital merupakan proses yang bertujuan untuk memanipulasi dan menganalisis citra digital dengan bantuan komputer". Penggunaannya, deteksi wajah mengunakan operator berbasis turunan pertama dan turunan kedua. Saat ini telah ada beberapa metode yang dapat digunakan dalam mendeteksi wajah, contohnya adalah metode Sobel dan Laplacian of Gaussian atau LoG, kedua metode ini cocok dalam menyelesaikan penghitungan komputasi. Kedua metode deteksi wajah ini menghasilkan citra yang berbeda, dimana citra yang dihasilkan metode Sobel lebih baik dan jumlah pixsel warna putih yang diperoleh lebih banyak dibandingkan dengan metode Laplacian.
\end{abstract}

Kata kunci : Citra, Deteksi wajah, Laplacian of Gaussian, komputasi, dan Sobel

\section{Pendahuluan}

Citra atau image, istilah lain untuk gambar, sebagai salah satu komponen multimedia yang berperan sangat penting sebagai bentuk informasi visual. Citra dari sudut pandang matematis, merupakan fungsi menerus atau continue dari intensitas cahaya pada bidang dua dimensi $\mathrm{f}(\mathrm{x}, \mathrm{y})$, dengan $\mathrm{x}$ dan $\mathrm{y}$ adalah koordinat spasial dan amplitude $\mathrm{f}$ pada pasangan koordinat $(\mathrm{x}, \mathrm{y})$ yang disebut intensitas atau derajat keabuan citra pada titik tersebut. Jika $\mathrm{x}, \mathrm{y}$, dan semuanya berhingga, dan nilainya diskrit, citra tersebut merupakan citra digital (Gonzalez et al ; 2004:2). Citra digital adalah citra yang disimpan dalam format digital atau dalam bentuk file. "Pengolahan citra digital merupakan proses yang bertujuan untuk memanipulasi dan menganalisis citra digital dengan bantuan komputer" (Fanzuanta, 2011:1).

Penggunaannya, deteksi wajah mengunakan operator berbasis turunan pertama dan turunan kedua. Saat ini telah ada beberapa metode yang dapat digunakan dalam mendeteksi wajah, contohnya adalah metode Sobel dan Laplacian of Gaussian atau LoG, dan sebagainya. Pembahasan dua buah metode deteksi wajah, yaitu metode Sobel dan Laplacian, karena kedua metode ini lebih mudah dalam menyelesaikan penghitungannya. Kedua metode deteksi wajah ini menghasilkan citra yang berbeda, dimana citra yang dishasilkan metode Sobel lebih 
baik dan jumlah pixsel warna putih yang diperoleh lebih banyak dibandingkan dengan metode Laplacian.

Metode Laplacian merupakan metode yang menggunakan operator Laplacian Operator Laplacian adalah operator yang berbasis gradien yang menggunakan dua buah kernel yang berukuran 3x3 pixel. Operator ini mengambil arah diagonal untuk penentan arah dalam penghitungan nilai gradient. Sedangkan metode Sobelmerupakan metode yang menggunakan operator Sobel. Operator ini menggunakan dua buah kernel yang berukuran $3 \times 3$ pixel untuk penghitungan gradiennya.

\section{Metode Penelitian}

Deteksi wajah dapat dipandang sebagai masalah klasifikasi pola dimana inputnya adalah citra masukkan dan akan ditentukan output yang berupa label kelas dari citra tersebut. Dalam hal ini terdapat dua label kelas, yaitu wajah dan non-wajah. Teknikteknik pengenalan wajah yang dilakukan selama ini banyak yang menggunakan asumsi bahwa data wajah yang tersedia memiliki ukuran yang sama dan latar belakang yang seragam. Di dunia nyata, asumsi ini tidak selalu berlaku karena wajah dapat muncul dengan berbagai ukuran dan posisi di dalam citra dan dengan latar belakang yang bervariasi. Pendeteksian wajah (face detection) adalah salah satu tahap awal yang sangat penting sebelum dilakukan proses pengenalan wajah (face detection).

Penelitian dari Nugroho dan kawan-kawan, mengelompokkan metode deteksi wajah menjadi empat kategori, yaitu :

1. Knowledge-based method. Metode ini kebanyakan digunakan untuk lokalisasi wajah,

2. Feature invariani approach. Metode ini kebanyakan digunakan untuk lokalisasi wajah,

3. Template matching method. Metode ini digunakan untuk lokalisasi wajah maupun deteksi wajah,

4. Appearance-based method. Metode ini kebanyakan digunakan untuk deteksi wajah.

\section{Citra Digital}

Citra dapat dikatakan sebagai citra digital jika citra tersebut disimpan dalam format digital (dalam bentuk file). Seperti halnya proses digitisasi dalam bentuk data lain, proses digitisasi pada data citra juga merupakan proses pengubahan suatu bentuk data citra dari yang bersifat analog ke dalam bentuk data digital, yang mana proses ini dapat dilakukan dengan alat bantu, yang salah satunya berupa kamera. Hanya citra digital yang dapat diolah menggunakan komputer. Jenis citra lain jika akan diolah dengan komputer harus diubah dulu menjadi citra digital. 


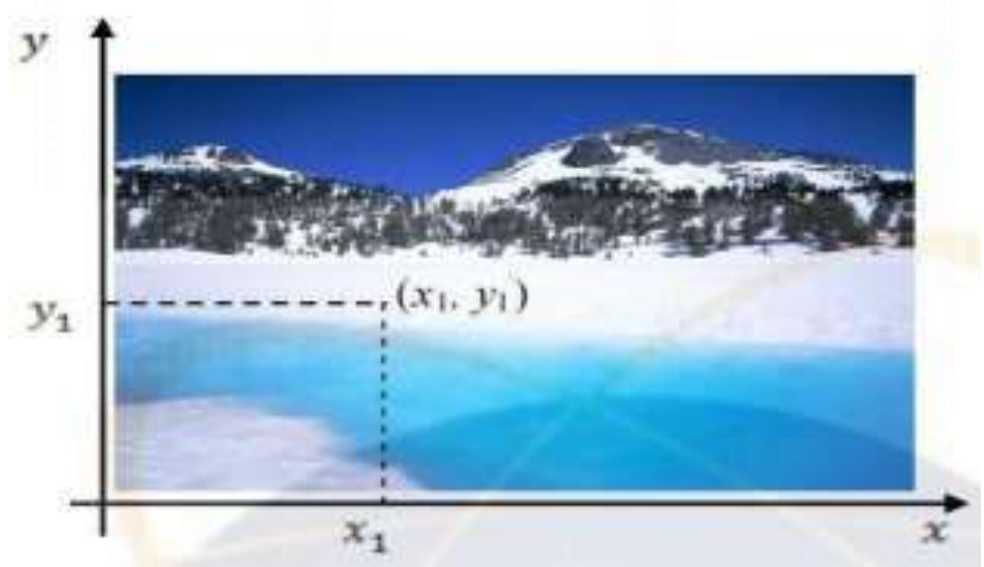

Gambar 2.1 Citra Digital(Citra Annisa, 2010)

Gambar 2.1 ditampilkan dengan matriks berukuran $\mathrm{N}$ x M (N menyatakan baris atau tinggi, $\mathrm{M}$ menyatakan kolom atau lebar) (Hestiningsih, 2008).

$$
f(x, y)=\left[\begin{array}{cccc}
f(0,0) & f(0,1) & \ldots & f(0, M-1) \\
f(0,1) & f(1,1) & \ldots & f(1, M-1) \\
\cdots & \cdots & & \ldots \\
f(N-1.0) & f(N-1,1) & \ldots & f(N-1, M-1)
\end{array}\right]
$$

Keterangan:

$\mathrm{N}=$ jumlah baris, $0=\mathrm{y}=\mathrm{N} 1 \mathrm{M}=$ jumlah kolom, $0=\mathrm{x}=\mathrm{M} 1$

$\mathrm{L}=$ maksimal warna intensitas (derajat keabuan), $0=\mathrm{f}(\mathrm{x}, \mathrm{y})=\mathrm{L} \quad 1$

Citra digital biasanya berbentuk persegi panjang, secara visualisasi dimensi ukurannya dinyatakan sebagai lebar x tinggi. Ukurannya dinyatakan dalam titik atau pixsel (pixel $=$ picture element $)$ dan dapat pula dinyatakan dalam satuan panjang $(\mathrm{mm}$ atau inci $=$ inch $)$.

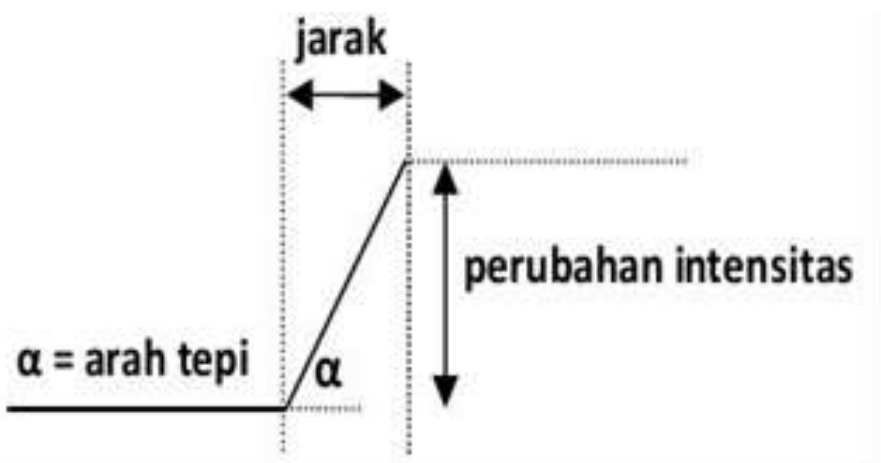

Gambar 2.11 Model Tepi Satu Dimensi (Febriani, 2008)

\section{Deteksi Tepi (Edge Detection)}

Secara umum tepi dapat didefinisikan sebagai batas antara dua region atau dua piksel yang saling berdekatan yang memiliki perbedaan intensitas yang tajam atau tinggi. Tepi dapat diorientasikan dengan suatu arah, dan arah ini berbeda-beda, tergantung Pada perubahan intensitas. Untuk lebih memahami defenisi tepi, gambar dibawah ini memperlihatkan model tepi dalam ruang satu dimensi (Febriani, 2008). 


\section{Langkah-Langkah Proses Pengimplementasian Aplikasi : \\ Rancangan Interface :}

1. Halaman utama digunakan untuk mengambil foto dari file, Form hasil: gambar atau foto yang akan diuji cobakan terhadap programnya Setelah berhasil mengambil foto dari file, maka foto tersebut akan diuji cobakan pada programnya.

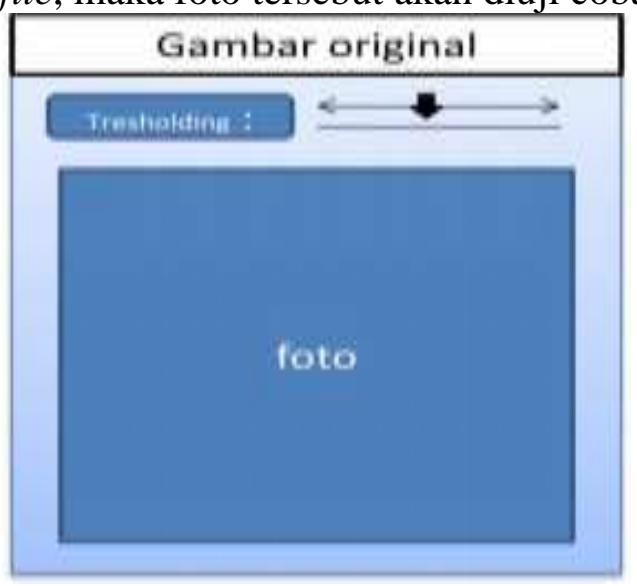

\section{Gambar 3.1 halaman utama}

2. Form hasil: hasil gambar atau foto yang telah diuji cobakan. Setelah foto diuji, maka akan terlihat perbandingan antara kedua metode Sobel dan Laplacian of Gaussian (LoG). Jadi antar kedua metode tersebut akan terlihat noise dan garis batas giometrinya dicontours.
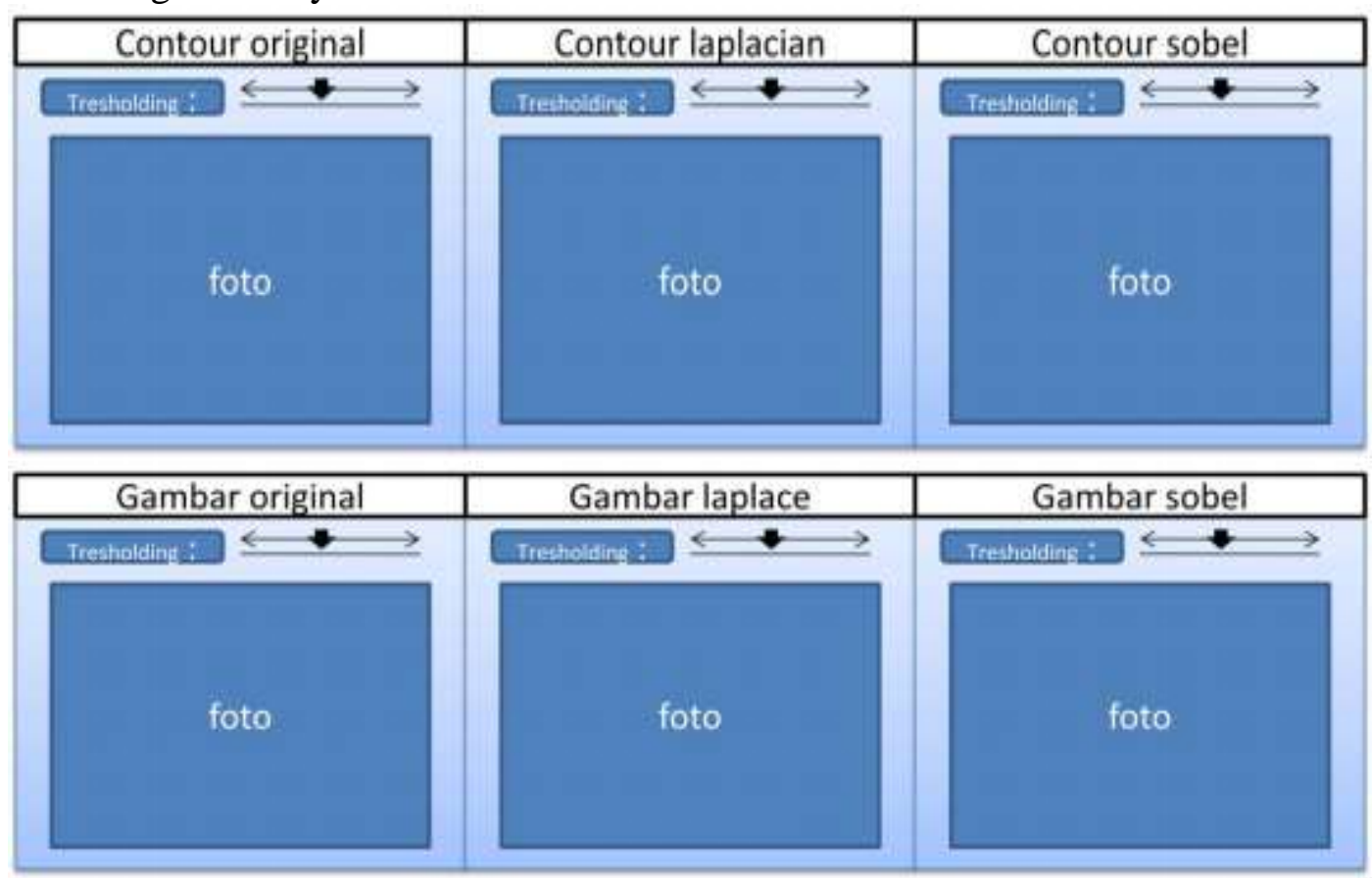


\section{Gambar 3.3 form hasil yang diuji antara metode Sobel dan Laplacian of Gaussian}

Berikut penjelasan langkah-langkah proses pengimplementasian pembuatan aplikasi ini . Untuk proses secara umum bisa digambarkan dengan diagram blok seperti berikut :

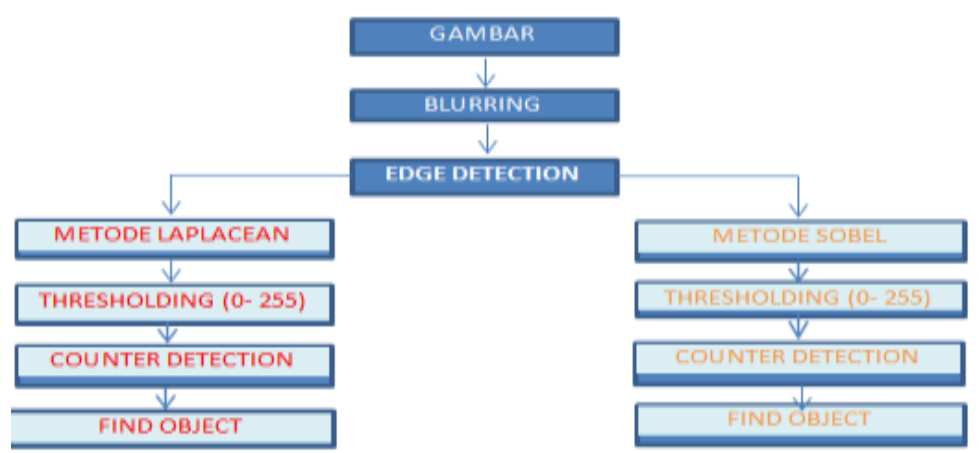

Gambar 3.10 Diagram Blok Proses Secara Umum

Pendefinisian, gambar akan menuju ke-blurring maka sebuah gambar antara metode laplacean of Gaussian dan sobel dengan thresholding antara 0-255 dan pendeteksian contours antara 2 metode tersebut kemudian munculah perbedaan gambar dengan menggunakan metode laplacean of gaussian dan metode sobel tersebut. Jadi unsure dari prosesnya dari kedua metode tersebut metode Sobel lebih akurat dibandingkan dengan metode Laplacian of Gaussian.

\section{Diagram Blok}

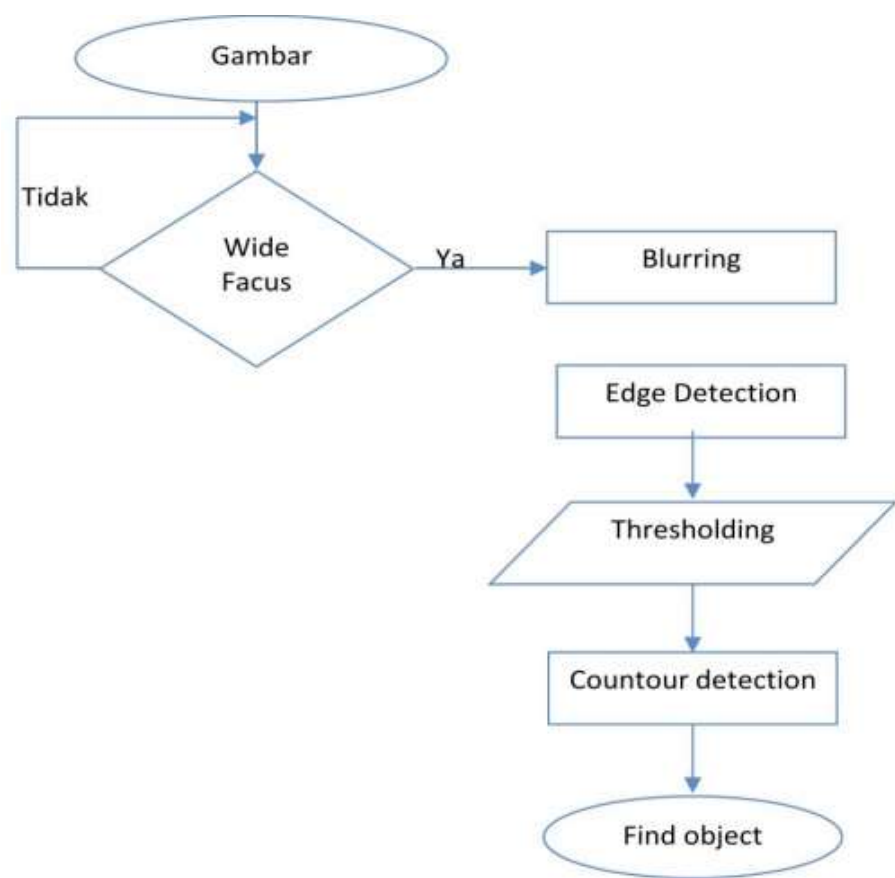

Gambar 3.10 Diagram Blok Proses 
Jika gambar ke wide facus benar maka lanjut ke blurring, jika gambar ke wide facus salah maka akan kembali lagi ke gambar, jika gambar benar maka akan lanjut ke blurring maka ke edge detection, lanjut lagi ke thresholding ke countour detection setelah semua benar maka akan ke find object. Average filter pada sebuah filter lowpass yang menghitung rata-rata, abu-abu (grayscale). Filter ini menggantikan nilai setiap pixel $[\mathrm{i}, \mathrm{j}]$ dengan rata-rata dari pixel di beberapa pixel tetangga di sekitarnya, yaitu jumlah bobot dari $[\mathrm{i}+\mathrm{p}, \mathrm{j}+\mathrm{q}]$, dengan $\mathrm{p}=-\mathrm{k} \mathrm{ke} \mathrm{k}, \mathrm{q}=-\mathrm{k}$ ke $\mathrm{k}$ untuk beberapa nilai $\mathrm{k}$ positif, bobot non-negatif dengan bobot tertinggi pada $\mathrm{p}=\mathrm{q}=0$. Penggunaan metode average filter diharapkan mendapatkan nilai yang rata dan sama pada tiap pixel tetangganya yang dihasilkan. Jika menggunakan metode filter lain, misalkan median filter atau Gaussian filter, mendapatkan proses yang berdasarkan nilai tengahnya pada tiap kernel tetangganya. Sehingga nilai tengah pada median filter atau Gaussian filter lebih besar dibandingkan dengan nilai tetangganya. Selain itu, median filter atau Gaussian filter kebanyakan berfungsi sebagai noise reduction atau mengurangi noise pada gambar.

Edge Detection Yaitu proses deteksi tepi pada suatu gambar yang menghasilkan gambarberupa garis garis tepi pada objek yang ada pada gambar. Metode untuk edge detection beragam. Pada aplikasi ini dengan menggunakan metode Sobel yaitudengan memanfaatkan kernel 3x3 sebagai berikut:

$$
\left[\begin{array}{lll}
0 & 0 & 0 \\
1 & 2 & 1
\end{array}\right]
$$

Pada matriks (2) ditampilkan sebagai filter vertikal.

$$
\left[\begin{array}{rrr} 
& & 2 \\
-1 & 0 & 1
\end{array}\right]
$$

Pada matriks (3) ditampilkan sebagai filter horizontal.

Untuk proses secara umum, contoh source code-nya seperti berikut :

/**@function main */

int main( int argc, char** argv )

\{

//initialitation value int scale $=1$;

int delta $=0$;

int ddepth $=$ CV_16S;

/// Load source image and convert it to gray

src = imread( "C:/gambar/10.jpg", CV_LOAD_IMAGE_COLOR);

/// Convert image to gray and blur it cvtColor( src,

src_gray, CV_BGR2GRAY ); blur( src_gray, src_gray,

Size $(3,3))$;

//sobel

Mat sobel_x, sobel_y;

Mat abs_sobel_x, abs_sobel_y;

// sobel X

Sobel(src_gray, sobel_x, ddepth, 1, 0,3, scale, delta,

BORDER_DEFAULT);

convertScaleAbs( sobel_x, abs_sobel_x ); // sobel Y

Sobel( src_gray, sobel_y, ddepth, 0, 1, 3, scale, delta,

BORDER_DEFAULT );

convertScaleAbs( sobel_y, abs_sobel_y ); 
/// Total sobel (approximate)

addWeighted(abs_sobel_x, 0.5, abs_sobel_y, 0.5, 0, sobel

);

Penggabungan edge detection dari 2 gambar yang diproses menjadi 1 gambar utuh untuk diproses lagi pada tahapan selanjutnya. Tampilan source code nya seperti berikut :

//sobel

Mat sobel_x, sobel_y;

Mat abs_sobel_x, abs_sobel_y;

// sobel X

Sobel( src_gray, sobel_x, ddepth, 1, 0, 3, scale, delta, BORDER_DEFAULT);

convertScaleAbs( sobel_x, abs_sobel_x ); // sobel Y

Sobel( src_gray, sobel_y, ddepth, 0, 1, 3, scale, delta, BORDER_DEFAULT);

convertScaleAbs( sobel_y, abs_sobel_y );

/// Total sobel (approximate)

addWeighted(abs_sobel_x, 0.5, abs_sobel_y, 0.5, 0, sobel );

Thresholding merupakan proses konversi citra grayscale menjadi citra biner (binary image) dengan nilai 1 dan 0 . Citra grayscale memiliki nilai intensitas warna antara 0-255 sehingga pada untuk memberikan nilai binary image pada citra ditentukan terlebih dahulu batas ambang yang akan membagi 2 daerah pada citra. Thresholding bertujuan menghasilkan citra biner secara matematis dapat dituliskan sebagai berikut :

$$
g(x, y)=\begin{aligned}
& 1 \text { if } f(x, y) \geq T \\
& 0 \text { if } f(x, y)<T
\end{aligned}
$$

Dengan $\mathrm{g}(\mathrm{x}, \mathrm{y})$ adalah citra biner dari citra grayscale $\mathrm{f}(\mathrm{x}, \mathrm{y})$ dan $\mathrm{T}$ menyatakan nilai threshold.

/// Detect edges using Threshold

threshold( abs_dst, threshold_output_laplace, thresh, 255, THRESH_BINARY);

/// Find contours

findContours( threshold_output_laplace, contours_laplace, hierarchy_laplace,

CV_RETR_TREE, CV_CHAIN_APPROX_SIMPLE, Point $(0,0)$ );

Contours Detection adalah garis batas dari bentuk geometric dalam gambar digital. Karena identifikasi kontur sangat penting untuk menganalisis isi gambar, ekstraksi kontur menjadi salah satu bagian penting dalam masalah computer vision dan pengenalan pola atau untuk objek gambar. Algoritma ekstraksi kontur terdapat dua tahapan utama. Tahap pertama dalah preprocessing untuk mengekstrak satu set poin berorientasi dari input gambar. Tahap kedua menentukan kontur diantara titik yang berorientasi menggunakan geometri. Tahap kedua tersebut masih terdiri lagi dari beberapa langkah yaitu titik saring dengan teknik pengelompokkan, selanjutnya titik dihubungkan berdasarkan kedekatan dan orientasi ke jalur yang mewakili kontur, dan akhirnya jalur yang disederhanakan dengan mengurangi jumlah titik yang mereka miliki ( Pedro et al, 2009, p 1 )

/// Find contours

findContours( threshold_output_sobel, contours_sobel, hierarchy_sobel, CV_RETR_TREE, CV_CHAIN_APPROX_SIMPLE, Point $(0,0))$; 


\section{Hasil Dan Pembahasan}

Citra yang dapat digunakan dalam percobaan untuk kedua metode wajah adalah citra dengan format JPEG (ekstensi *.jpg). Pengujian gambar yang dilakukan dengan membagi gambar dengan kamera - kamera yang berbeda dan metode yang berbeda juga. Seperti menggunakan kamera hp berbagai merek dengan perbedaan pada pixel pada kamera tersebut, dan mengunakan kamera digital dan DLSR berbagai merek dan spesifikasi.

\section{Perbandingan Citra Hasil Deteksi Wajah Secara Visual}

Semua data uji, citra yang diperoleh dari hasil metode Sobel lebih jelas dan garis tepi yang diperoleh lebih banyak terhubung disbanding dengan metode laplacian yang masih putus-putus. Dengan menggunakan metode Sobel, masih banyak tepi yangbisa terbaca disbanding dengan metode Laplacian.

Metode Sobel lebih baik dibandingkan metode Laplacian karena operator dan ukuran kernel yang digunakan berbeda. Metode Sobel menggunakan operator Sobel:

$$
\mathrm{Sx}=\begin{array}{rrrrrr}
-1 & 0 & 1 & 1 & 2 & 1 \\
-2 & 0 & 2 \\
-1 & 0 & 1 & -1 & -2 & -1
\end{array} \text { dan Sy } \begin{array}{rrrr}
-2 & 0 & 2
\end{array} \text { dengan ukuran } 3 x 3 \text { pixel. Sedangkan }
$$

Metode Laplacian of Gaussian menggunakan operator Laplacian Of Gausian

$$
\begin{array}{llllll}
0 & -1 & 0 & 0 & 1 & 0
\end{array}
$$

$\mathrm{Lx}=\begin{array}{llllllll}0 & 4 & -1 & \text { dan } \mathrm{Ly}=0 & 1 & 0 & \text { dengan ukuran kernel } 3 \mathrm{x} 3 \text { pixel }\end{array}$

$\begin{array}{llllll}0 & -1 & 0 & 0 & 1 & 0\end{array}$

Metode laplacian lebih menekankan penghitungan gradient arah diagonal sedangkan metode Sobel lebih kearah vertical dan horisontalnya. Ukuran kernel yang dipakai dalam deteksi wajah cukup mempengaruhi hasil yang didapat, semakin besar ukuran kernel semakin banyak wajah yang diperolah, terbukti dalam percobaan lain ketika mendeteksi wajah dengan menggunakan kernel berukuran 3x3 pixel pada citra.

\section{Kesimpulan Dan SARAN}

Berdasarkan pembahasan yang telah diuraikan, maka diambil beberapa kesimpulan:

1. Kualitas citra grayscale untuk face detaction

a. hasil Operator $L o G$ menghasilkan tepi citra wajah yang sama jelasnya dengan operator Sobel dan Operator Sobel memproses tepi citra wajah lebih cepat dibandingkan operator $L o G$.

b. bergantung pada jumlah cluster yang diberikan dalam proses pengolahan citra, pemilihan kategori citra acuan yang ditentukan dan pengaruh dari masingmasing citra dalam kategori yang sama.

2. Pengujian face detaction berdasarkan analisa gambar dan analisa counturs yang telah dilakukan dapat disimpulkan bahwa penerapan metode sobel lebih baik dibandingkan dengan penerapan metode Laplacian of Gaussian dalam pewarnaan citra face detiction. 


\section{Daftar Pustaka}

Viola, P.,Jones, M. J. 2004. ROBUST REAL-TIME FACE DETECTION, International Journal of Computer Vision, Kluwer Academic, Netherlands.

Charan, BP., Sinha ,G.R., 2010, An Adaptive K-means Clustering Algorithm for Breast Image Segmentation, Int. Journal of Computer Applications, 10(4).

Gonzalez, R.C., Woods, RE., 2008, Digital Image Processing Third Edition, Pearson Prentice Hall, London. Putra, D.,2010,

Pengolahan Citra Digital, Andi Yogyakarta. Yogyakarta. Russ, JC., 2011,

The Image Processing Handbook Sixth Edition, CRC Press. United State. Sheikh, H.R., Bovik A.C., 2005,

Information Theoretic Approaces to Image Quality Assessment. In: Bovik, A.C. Handbook of Image and Video Processing. Elsevier. Srini, 2009.,

Nugroho, S. 2004. SISTEM PENDETEKSI WAJAH MANUSIA PADA CITRA DIGITAL, Tesis Program Studi Ilmu Komputer Jurusan MIPA, Universitas Gadjah Mada, Yogyakarta

Pengolahan Citra: Konsep Dasar, http://srini.staff.gunadarma.ac.id/Downloads/files/ 4881/8+Olah+Citra-Konsep+Dasar.pdf, diakses 9 Maret 2011 Suhendra, A.,2008,

Akbaramin, Muhammad. 2012. Analisa Perbandingan Kinerja Deteksi Tepi Menggunakan Metode Log, Sobel, Dan Canny Terhadap Format File Jpeg Dan Bmp. (Online). (diakses 25 Januari 2017).

Catatan Kuliah Pengantar Pengolahan Citra, http://images.analyst71. multiply.com/attachment/0/Rz6WgoKCiQAAFxBe81/Catatan\%20Kuliah\%20P C\%202007.pdf, diakses 9 Maret 2016 